\title{
Role of physical therapy in overcoming the barrier and adaptive behaviour for return to work in subjects with non-specific chronic low back pain: A qualitative study
}

\author{
Waseem Mumtaz Ahamed', Shadab Uddin*1, Fuzail Ahmad² and Kenneth Chance-Larsen ${ }^{3}$ \\ ${ }^{1}$ Department of Physical Therapy, Faculty of Applied Medical Sciences, Jazan University, Jazan, Kingdom of \\ Saudi Arabia. \\ ${ }^{2}$ Department of Physical Therapy \& Health Rehabilitation, College of Applied Medical Sciences, Majmaah \\ University, Al Majmaah, Kingdom of Saudi Arabia. \\ ${ }^{3}$ School of Health Sciences, Associate Professor, Allied Health Program Leader, Central Queensland \\ University, Australia
}

\begin{abstract}
Clinical investigation has revealed that individuals face challenges in adapting to their gruesome employee-roles after undergoing a back intervention program. The aim of this research was to investigate the back-rehabilitated patient's perspectives and understandings of the difficulties faced while adapting as employees. Research aimed to extract the patient's perspectives and understandings of barriers, facilitators and adaptive procedures which influenced their capability to continue their employee-roles. Qualitative investigation method was used for investigating the study topic. Focus groups comprised of broad questions followed by probing were utilized to obtain detailed descriptions about the client's understandings and perspectives. Recommendations involved developing the insight of stakeholders regarding early, valuable on-job training, initiating health-promotion by teaching in the workplace and in the society, along with improving flexible job and health policy. Results of the investigation signify that the goal of physiotherapy and extent of service to back injured patients needs to rebuild.
\end{abstract}

KEY WORDS: BACK INJURED PERSON, BACK REHABILITATION, BARRIERS, FACILITATORS AND ADAPTIVE PROCEDURES

\section{ARTICLE INFORMATION:}

Corresponding Authors: ssabauddin@jazanu.edu.sa drshadabuddins@gmail.com

Received $12^{\text {th }}$ Oct, 2018

Accepted after revision $23^{\text {rd }}$ Dec, 2018

BBRC Print ISSN: 0974-6455

Online ISSN: 2321-4007 CODEN: USA BBRCBA

Thomson Reuters ISI ESC / Clarivate Analytics USA

: Mono of Clarivate Analytics and Crossref Indexed Journal Mono of $C R$

NAAS Journal Score 2018: 4.31 SJIF 2017: 4.196

- A Society of Science and Nature Publication, Bhopal India 2018. All rights reserved.

Online Contents Available at: http//www.bbrc.in/

DOI: $10.21786 / \mathrm{bbrc} / 11.4 / 12$ 


\section{INTRODUCTION}

Industrialization has resulted in increasing number of back disabilities especially within industries which need frequent carrying of heavy substances. Back injury is quoted as the costliest health concerned problem within people aged between 30-50 years and the primary reason of disorder within population less than 45 years of age (Jones and Kumar, 2002). Back pain which persists for lesser than 3 months can be called 'acute' because a person can improve without therapeutic treatment (Drezner \& t Herring, 2001). The growth of a chronic condition can be associated with fear of recurrence of injury, excessively caring partners and being aware of sickness role (Joy et al., 2000). It can hence, be debated that such supporting aspects lead to an inadequate return to work rate especially if people are being financially compensated for their losses.

As per Friesen et al. (2001), employee attitudes and motivation to participate must be acknowledged and addressed if more injured employees are to be successful within return to permanent employment. Henceforth, theories based on the patient's motivation were viewed as being of value during investigating returning to work process. Cognitive theories of motivation have been recommended as suitable constructs to understand individual dissimilarities in motivation within return to work behaviour following work injury (Roessler, 1989). It signifies that an employee's personal viewpoint of himself within context of being re-injured in the work atmosphere plays an influential part within returning to work process. Research has revealed that money in form of worker's compensation or legal actions can also behave as a motivator for pain behaviour, (Reneman, 2001 Cancelliere et al., 2016 Wong et al., 2017).

It signifies that pain faced by some back injured subjects is worthwhile within itself due to the economical rewards, empathy, notice and concern it creates in favour of such subjects. As per Hildebrandt (1998), efficacy of present intervention strategies have not been proven considerably and it is apparent within yearly rise of patients having Chronic Low Back Pain (CLBP). This could be assumed that earlier back pain studies have strong efforts on rehabilitation from a health-expert's viewpoint, failing to comprehensively realise the back injured client's perceptions or views during planning treatment approaches, (Gatchel 2018).

Therefore this study is aimed to extract patient's perspectives and understandings of barriers, facilitators and adaptive procedures which influenced their capability to continue their employee-roles.

Methods: Qualitative investigation method was used for investigating the study topic. Subjects were chosen through random sampling from S.M.S (Sawai Man
Singh) Hospital, Jaipur, Rajasthan, India -Physiotherapy Department. Focus groups comprising of broad questions followed by probing were utilized in order to obtain detailed descriptions about the client's understandings and perspectives. A pilot testing group and 3 one-hour focus groups were conducted consisting of 5 subjects in each group on an average. Data which was produced was qualitatively examined by manual coding system to achieve codes, categories and themes. Aspects which were viewed as facilitators involved enhanced communication and precision between stakeholders, injury prevention approaches and understanding among stakeholders which facilitated team-work. Aspects which obstructed subjects to resume as employees were considered to be barriers. These involved delays and all kinds of inefficacy for instance, inadequate management processes, bad quality medical treatments and uncaring work atmosphere.

Study-design: As explained by Bailey (1997), a qualitative investigation illustrates multiple realities and interpretations that aimed to enhance an in-depth understanding of the perceptions and knowledge of the participants. Because of this, a qualitative investigation concept was selected to conduct this research. Objective of this research asked for a qualitative-methodological-analysis to be performed because the highlight was on illustrating the perspectives and understandings of back-rehabilitated subjects on their return to workplace.

\section{DATA COLLECTING PROCEDURE}

Focus group Interview: Focus group interview was chosen for collecting data. Because of its interacting nature they are an ideal method to explore participant's own meaning and to understand issues like health and illness. This method of investigations is mainly helpful to assess the viewpoints of those who have been inadequately served by a traditional research Wilkinson (1998). Pilotfocus group interviewa were conducted, to provide a direction towards establishing a range of approaches that were essential in order to investigate aims of the research. When no issues were established within questions of pilot focus group, minor modifications were done to the questions of the focus groups which followed. Data obtained from the pilot focus group was included in the study in order to contribute to aim of the research.

Participants: Participants were selected from statistical records of S.M.S Hospital-Physiotherapy Department. Since it is the largest and only government Hospital situated in Jaipur (capital of Rajasthan, the largest state of India), it was ideal for selecting subjects having workrelated pain for this research. Because of the fact that a number of subjects with different kinds of injuries are assessed at the hospital, subjects having only back pain 
were selected from statistical records of the hospital. Aim of the study was described to the participants on telephone by contacting them at their place of work, if employed or at their residence, if unemployed.

Sampling: Simple random sampling (Kerlinger 1986), was utilized as a procedure in order to give every patient on statistical records of the hospital, an equivalent opportunity to be selected in the research. A table of random digits were used to select the subjects which was followed by giving a number to each name. A random start-point had been selected on a random table and first 24 numbers and the names that corresponded them were selected. After that, subjects that were chosen were invited to take part within this project.

Sample size: According to Krueger (1994), an ideal number of participants in a focus group ought to be between 3 and 9, therefore for this study 24 participants (8 participants per group) were selected to be involved within the 3 focus groups. However, only 15 participants turned up for the interview.

Selection Criteria: The inclusion criteria for this study were; subjects with a medically diagnosed chronic back pain affecting their work, who had received medical and physical therapy treatment. Subjects were not included if they had any form of psychiatric diagnosis, or undergone any invasive or surgical treatment for chronic back pain because their quality of life and psychosocial adaptations as employees could have provided an unhelpful influence on the investigation.

Study Protocol: A pilot testing group and 3 one-hour focus groups were performed and an average of 5 participants attended each group. It was done to serve the purpose of discovering the perspectives and understandings of a range of participants, hence to ensure dissimilarity among the views of study participants. Broad questions were asked which was followed by probing for eliciting detailed and rich explanations. A kind of debriefing was included at the end of each session, in which subjects were facilitated to clear their queries and express their feelings of contributiion within a group.

Focus groups were performed within one of the consulting rooms of physiotherapy department as the venue was familiar to all the subjects. As per the convenience of the subjects, the group session were scheduled every afternoon between 2-3 pm, for three continuous days. Subjects were seated around a table ensuring that there was a proper eye contact. Name tags were given to build a rapport between subjects. An audiotape was put at a pre-meditated position so that all the data received could be free from unrelated external stimuli.

Focus group questions were offered to clients both in English and Hindi. Subjects were informed that they were free to withdraw their consent before participating or at any stage of discussions. Participants were introduced to each other so that they could unwind themselves and become familiar to each other and to the environmental setting. Investigator set goals for discussion and guaranteed the clients that their feelings and views will be valued. Questions were discussed with the tutor in advance and changes were made accordingly. This allowed the investigator to become conscious of several group-dynamics that could play an important part, for e.g. difference between traditions, attitude towards life and viewpoints.

Data-analysis: Within this investigation, 4 cognitive procedures allowed the investigator to examine the qualitative data through comprehending, synthesizing (de-contextualizing), theorizing and re-contextualizing (Morse Et Field, 1996).

Comprehending: Transcriptions were done directly after interviewing, providing investigator the time to study as well as identify the interviewed data before arranging for the next interview. After that, information was coded through line-by-line analysis to discover essential meanings within the transcript. Then, the investigator became capable of identifying the experiences that are a part of the research investigation and the patterns that foresee possible outcomes.

De-contexualizing: This phase was achieved at the completion of third focus group. Transcripts were evaluated during analysing, where codes were built into categories through commonalities, consisting of segments of transcripts.

Theorizing: Different descriptions were investigated against the data until the data for the research was best described. Questions were asked on the data for establishing links to the theory. This organized procedure facilitated the investigator to inductively develop formal themes from data. This also allowed investigator to acknowledge the quality of data to contribute within a particular experience or perspective.

Re-contextualizing: Comparing the similarities and dissimilarities between the data and the published research of other investigators played an essential role to ensure credibility of the data. Investigator made an effort to put the outcomes of the investigation within the context of standard knowledge and appreciated the outcomes which supported the literature.

\section{RESULTS}

\section{THEMES}

The themes of the research directly associated to the research aim and investigate the difficulties that back- 
Table 1. Demographic and Clinical Data of participants

\begin{tabular}{|l|l|l|l|}
\hline Variable & Category & $\begin{array}{l}\text { Number of subjects in pilot } \\
\text { group(m=men/w=women) }\end{array}$ & $\begin{array}{l}\text { Number of subjects in focus } \\
\text { groups (m=men/w=women) }\end{array}$ \\
\hline \multirow{2}{*}{ Gender } & Men & 3 & 7 \\
\cline { 2 - 4 } & Women & 0 & 5 \\
\hline \multirow{2}{*}{ Age in years } & & $\begin{array}{l}18-40=2(\mathrm{~m}) \\
41-65=1(\mathrm{~m})\end{array}$ & $\begin{array}{l}18-40=5(\mathrm{~m}), 41-65=2(\mathrm{~m}), 18-40=3 \\
(\mathrm{w}), 41-65=2(\mathrm{w})\end{array}$ \\
\hline \multirow{2}{*}{ Employed } & Yes & 2 & $8(\mathrm{~m}), 3(\mathrm{w})$ \\
\cline { 2 - 5 } & No & 1 & $2(\mathrm{~m}), 2(\mathrm{w})$ \\
\hline \multirow{2}{*}{ Medical Intervention } & $\begin{array}{l}\text { Type of organizations } \\
\text { in which rehabilitation } \\
\text { was obtained }\end{array}$ & $\begin{array}{l}\text { D.H }=1(\mathrm{~m}) \\
\text { B.R.F }=2(\mathrm{~m})\end{array}$ & $\begin{array}{l}\text { D.H=4(m), 2(w) } \\
\text { B.R.F=2(m), } 1(\mathrm{w}) \\
\text { P.T=1(m), 2 (w) }\end{array}$ \\
\hline Data collection & No. of focus groups & 1 session & $\begin{array}{l}3 \text { sessions (different clients in each } \\
\text { group) }\end{array}$ \\
\hline "Key : D.H - (Day Hospital), B.R.F - (Back Rehabilitation Facility), P.T - (Physiotherapy consultant in a home visit)
\end{tabular}

rehabilitated individuals came across on their return to work. Theme one associates with the barriers which obstructed back injured individual's adaptation as employees, theme two associates with the facilitators which supported individuals to adapt to their employeeroles, theme three associates with the individual's perceptions and experiences of adapting to their role as employees. Table 2 present the themes which emerged after the data-analysis

Barriers: Fisher (1994) documented that psycho-social maladjustment and psychological health of an injured employee can be revealed within perspectives generated in reaction to depressing or destructive social aspects. By the information obtained, this was apparent that client's perspectives of themselves concerning their capability to execute job-associated tasks were either pessimistic or optimistic. Subjects frequently mentioned that unhelpful perceptions of employers as well as society forced them in losing self-confidence and build a feeling of uncertainty within their performance capabilities.

Doleys \& Gochneaur (1989) describes that not everybody who has an injury develops a chronic condi-

Table 2. Themes categorizing the difficulties of back-rehabilitated individuals affecting their return to work.

\begin{tabular}{|c|c|c|}
\hline Themes & Category & Subcategory \\
\hline \multirow{4}{*}{$\begin{array}{l}\text { 1. Barriers (Feeling of } \\
\text { Uncertainty) }\end{array}$} & \multirow{2}{*}{$\begin{array}{l}\text { 1. Feeling of uncertainty by } \\
\text { stakeholders }\end{array}$} & $\begin{array}{l}\text { Employer building an uncaring approach and uncertainty in } \\
\text { the employee. }\end{array}$ \\
\hline & & $\begin{array}{l}\text { Health-service building an uncaring approach and } \\
\text { uncertainty in the client's condition }\end{array}$ \\
\hline & \multirow{2}{*}{$\begin{array}{l}\text { 2. Uncertainty in own } \\
\text { potentials for accomplishment } \\
\text { at work }\end{array}$} & Uncertainty in return to work approaches \\
\hline & & $\begin{array}{l}\text { Uncertainty in discovering a meaning within the employee- } \\
\text { role }\end{array}$ \\
\hline \multirow{4}{*}{$\begin{array}{l}\text { 2. Facilitators } \\
\text { (Approaching an idealistic } \\
\text { rehabilitation-program) }\end{array}$} & \multirow{2}{*}{ 1. Informed stakeholders } & Informed employers \\
\hline & & Informed consultants \\
\hline & \multirow{2}{*}{ 2. Work promoting approaches } & Multi-trained health-experts \\
\hline & & Pain and disorder evaluation teams \\
\hline \multirow{4}{*}{$\begin{array}{l}\text { 3. Adaptors } \\
\text { (Self-Responsible) }\end{array}$} & \multirow[b]{2}{*}{ 1. Managing yourself } & Reorganising yourself \\
\hline & & $\begin{array}{l}\text { Building an optimistic view and accepting your clinical } \\
\text { condition }\end{array}$ \\
\hline & \multirow{2}{*}{$\begin{array}{l}\text { 2. Building competency in your } \\
\text { employee-role }\end{array}$} & Awareness and training of the employee \\
\hline & & Asserting yourself \\
\hline
\end{tabular}


tion. Instead, a feeling of external sense of control while performance participation results in a sense of insufficiency and it depicts itself within the employee not being able to control the pain. By such a perception, it could be assumed that an external feeling of control in which client's certainty within himself in continuing his employee-role was affected by the perspectives of others in the environment. Such an uncertainty affected the person's feelings of self-efficacy during executing jobassociated tasks.

Bandura (1989) debated that self-efficacy expectations powerfully influence motivation. Few subjects in present investigation were inadequately motivated in returning to work after injury. Such inadequate motivation can be seen as a consequence of barriers for instance, their uncertainty in opportunities after being injured. Subjects felt that they had not been capable enough in performing job-tasks which they did earlier. A sub-category 'uncertainty in return to work approaches' interprets their perspectives of fear in which they perceived that recurring injury might cause increase in pain and restrictions which can impact on their economical and psycho-social conditions. Such perceptions caused the subjects to avoid tasks in the workplace and lose confidence within their own potentials and capabilities.

Such results correspond to those of Fritz and George (2002) who examined fear-avoiding beliefs, and came to a conclusion that these are significant variables within foreseeing client's achievement within treatment programs. It henceforth, signified that subjects who feared re-injury may face problems to complete rehabilitation programs and can be at risk of long-lasting work limitations. Nevertheless, Forman \& Murphy (1996) view the person as an aware agent that vigorously understands the environmental requirements and behaves accordingly with these perspectives. An implication of this would be that a person builds an internal sense of control whereby he obtains encouraging response from the environment and builds a constructive self-perception as well. Such a constructive self-perception reflected within approach of the subjects during completing intervention programs as well as during return to work. Subjects perceived that an optimistic approach along with internal motivation supported them to effectively complete intervention programs.

Facilitators: Subjects who performed productively in the work atmosphere repeatedly mentioned injury prevention as a facilitator. Injury prevention in terms of this research involved positive communication and confidence within stakeholders who were directly in touch with the worker. The participants described that the interpersonal-relations between the stakeholders con- firmed that their treatment programs were frequently supervised and hence, promoted a quicker return to work rate.

\section{DISCUSSION}

This result is similar to a research by Friesen et al. (2001) in which interaction, team-effort, faith and sincerity were established to be supportive aspects during return to work-process. Such aspects henceforth, decided success by connecting the gaps for the patient from treatment processes to participating as employees. Conventional health-service has concentrated on a bio-medical model of rehabilitation in which a person's elements of performances have been remediated for participating in their work roles for instance, an employee, homemaker, sportsperson, etc. (Smithline \& Dunlop, 2001, Cancelliere et al., 2016). Physiotherapy consultants working in private as well as for the government are frequently pushed for time due to excessive patient loads that they are bound to tackle with. It frequently leads to physiotherapists finding hard to perform holistic assessment processes like identifying the outcomes of work atmosphere and home atmosphere on the back injured client's performance. Physiotherapy consultants are in a favourable situation of being capable of incorporating holistic assessment and treatment in an individual's functioning as an environmental frame of reference (Christiansen, 1997, Gatchel 2018).

Nonetheless, consultants who desire to practice a career in comprehensive evaluation and intervention of an injured worker are required to focus on particular courses on ergonomic assessment of the injured employee's workplace as well as develop their focus on government laws for example, employment justice, code of high-quality service and workplace safety. Focus into such courses and government laws would enable physiotherapists in empowering their back injured patients within context of their legal rights at workplace and would facilitate them to adapt and retain their employee-roles. By a rise within workers taking legal action against companies concerning workplace injuries and unjustified removal, physiotherapists can be invited in future to give specialist legal authentication on basis of a person's work performance.

The results signified that the subjects which were successful to resume work after pain-process received a caring atmosphere at home and in workplace. This meant that barriers which impacted on the injured were mostly environmental in nature and such barriers were viewed as challenging when it influenced subjects personally. A majority of subjects within this research showed a powerful internal sense of control and it was visible within their capability to be responsible for their own treatment. 
Nonetheless, they had to adjust regardless of working in an unsupportive working atmosphere. According to their perspective, they kept trying by searching meaning within the work that they were occupied with, by precise work-placement strategies, managing injury on their own and keeping a powerful value system which enabled them to resume their tasks. Physiotherapists, with their understanding about pathology and jobplacement strategies have a high influence within the occupational treatment field. This will be their duty to facilitate an injured person in precisely identifying their difficulties and assets with regard to their capabilities and suitably match it to the job requirements. Subjects in the investigation presented with restrictions concerning the physical aspects of their performances such as to bend, to carry and to climb. It forced the back injured to observe increasing back pain. Physiotherapist will in turn support the back injured to modify the person's substantial and psycho-social job surroundings. Physical adaptation was viewed as modification of equipment and structural environment of the worker to equalise their performance capabilities. Psycho-social adaptation was viewed as informing the manager and the employee concerning the depressing outcomes of an unhelpful working atmosphere on the back injured person. Physiotherapist will henceforth, be capable of consulting with other rehabilitation-experts as well as employers within context of most appropriate job-placement and dealing with approaches of back injured people.

Health-promotion was considered to be a potential structure of recommendation for building a caring atmosphere for back injured people. Back injured client's workplace and home was considered to be examples of a caring atmosphere in which preventing back disorders and reinforcing intervention procedures can be initiated. Back injured people have presently been on a risk for not identifying their potentials because they do not use their complete mental/emotional as well as physical capability at work. Such capability in terms of this research can henceforth, only be remediated by enhancement of a caring society and a supportive work atmosphere.

\section{CONCLUSION AND FUTURE RECOMMENDATIONS}

The main aim of the research was to build a larger focus into the issues which challenge the back injured individuals. Results of the investigation signify that the goal of physiotherapy and extent of service to back injured patients needs to rebuild.

\section{REFERENCES}

Bailey, D.M. (1997). Research for the health professional: a practical guide, 2nd edition. Philadelphia: F.A. Davis Company.
Bandura, A. (1989). Human agency in social cognitive theory. American Psychologist, 44, 1175-1184.

Cancelliere C., J. Donovan, M. Jensen Stochkendahl, Melissa Biscardi,Carlo Ammendolia,Corrie Myburgh,and J. David Cassidy (2016) Factors affecting return to work after injury or illness: best evidence synthesis of systematic reviews, Chiropr Man Therap. 2016; 24(1): 32.

Doleys, D.M. And Gochneaur, K.S. (1989). Behavioural management. In Tollison, M.L. \& Kriegel, C.D. (Eds) Interdisciplinary rehabilitation of low back pain. Baltimore: Williams and Wilkins.

Drezner, J. And Herring, S. (2001). Managing low back pain. Physician and Sports Medicine, 29 (8), 37-44.

Finneson, B. (1980). Low back pain, 2nd edition, Philadelphia: J.B. Lippincott Co.

Fisher, T.F. (1994). Industrial Rehabilitation: A natural environment for physiotherapy practitioners, Work, 4, (4), 259263.

Forman, P. And Murphy, G. (1996). Work values and expectancies in occupational rehabilitation: The role of cognitive variables in return to work process. Journal of Rehabilitation, 62, (3), 44-48.

Friesen, M.N., Yassi, A. And Cooper, J. (2001). Return to work: The importance of human interactions \&t organisational structures. Work, 17, 11-22.

Fritz, J.L. And George, S.Z. (2002). Identifying psychosocial variables in patients with acute work related low back pain: The importance of fear avoidance beliefs. Physical Therapy, 82, (10), 973-981.

Gatchel R J (2018) Low Back Pain,: Recent Advances and Perspectives Robert J. Gatchel www.mdpi.com/journal/ healthcare,Edited by Robert J. Gatchel www.mdpi.com/journal/healthcare, MDPI AG St. Alban-Anlage 66 Basel, Switzerland

Hildebrandt, J. and Pfingsten, M. (1998). Backache-diagnoses, therapy and prognosis, 92, (1), 13-22.

Christiansen, C. and Baum, C. (1997). Enabling function and well being, 2nd edition, Thorofare: Slack incorp.

Isernhagen, S.J. (2000). Matching the worker and the work benefits to the worker: Benefits to the employer. Work, 15, 125-132.

Jones, t. and Kumar, s. (2001). Physical ergonomics in low back pain prevention. Journal of Physical Rehabilitation, 11, (4), 309-319.

Joy, J.M., Lowy, J. and Mansoor, J.K. (2000). Increased pain tolerance as an indicator of return to work in low back injuries after work hardening, 55, (2), 200-205.

Kerlinger, F.N. (1986). Foundations of behavioural research, 3rd edition, Fortworth: Harcourt.

Kruger, R.A. (1994). Focus groups, 2nd edition, Thousand Oaks: South Africa:Sage.

Linton, S.J. (1990). Risk factors for neck and back pain in a working population in Sweden. Work Stress, 4, 41-49. 
Morse, J.M. And Field, P.A. (1996). Nursing research: The application of qualitative approaches, 2nd edition. London: Chapman \& Hall.

Reneman, M.F., Dijkstra, S.J., Jorritsma, W., Muskee, C., Schiphorst, Preuper, M.I. And Goeken, L.N.H. (2001). Assessment and treatment of chronic work related pain disorders in an outpatient university rehabilitation setting in the Netherlands. Work, 16, 23-30.

Roessler, R.T. (1989). Motivational factors influencing return to work. Journal of Applied Rehabilitation Counselling, 20 (2), 14-17.
Smithline, J. and Dunlop, L.E. (2001). Low back pain. In: Pedretti, L.W. \& Early, M.B. (Eds) Physiotherapy: Practice skills for physical dysfunction. (5th edition). Missouri: Mosby.

Wilkinson, S. (1998). Focus group research-exploring the meanings of health \& illness. Journal of Health Psychology. 3, (3), 329-348.

Wong YL Arnold, Jaro Karppinen and Dino Samartzis (2017) Low back pain in older adults: risk factors, management options and future directions Scoliosis Spinal Disord. 2017; 12: 14 . 